Journal of Clinical Pathology, 1978, 31, 1239-1243

\title{
Platelet aggregation in chronic idiopathic thrombocytopenic purpura
}

\author{
A. DU P. HEYNS, J. FRASER, AND F. P. RETIEF \\ From the Departments of Haematology and Internal Medicine, Faculty of Medicine, University of the \\ Orange Free State, Bloemfontein 9300, South Africa
}

SUMMARY A method for washing platelets by albumin density gradient separation has been modified to prepare platelet rich plasma of thrombocytopenic patients for platelet aggregation studies. The concentration procedure, consisting of centrifuging platelets into a specific gravity gradient between plasma and $40-45 \%$ aqueous solution of bovine albumin, does not affect platelet aggregation adversely. Platelet aggregation in eight patients with chronic idiopathic thrombocytopenic purpura was determined by this method. On the basis of the results the patients could clearly be divided into two groups: four patients with normal aggregation and four with a qualitative platelet defect. In contrast to the other patients, the group with an in vitro platelet functional defect all had more prolonged bleeding times and the presence of a serum antiplatelet antibody.

The most widely applied technique for investigating platelet function in vitro is the aggregation method introduced by Born (1962). This method, however, requires a reasonably high concentration of platelets in the platelet rich plasma (PRP) and can thus not be applied as such for the investigation of patients with thrombocytopenia. We describe a method used by Walsh (1972) for studying platelet coagulation activities, which was modified and adapted to concentrate platelets in cases of thrombocytopenia. After assessment of the efficiency of the concentration technique and its influence on in vitro platelet aggregation it was applied in a study of platelet aggregation in patients with chronic immune type idiopathic thrombocytopenic purpura.

\section{Material and methods}

PREPARATION OF PRP (Heyns et al. 1974)

Blood was obtained by clean venesection with disposable polystyrene syringes and siliconised needles from normal human volunteers or patients who had not taken aspirin or any other drugs known to affect platelet function for at least two weeks before the test. Ten parts of venous blood were added to one part $3.13 \%(\mathrm{w} / \mathrm{v})$ trisodium citrate in polystyrene test tubes. The samples were centrifuged at room temperature for 15 minutes at $160 \mathrm{~g}$ (PRP) and platelet poor plasma (PPP) was prepared by centrifugation at $2500 \mathrm{~g}$ for 20 minutes. Test PRP

Received for publication 30 May 1978 was prepared by adjusting the platelet count of PRP to that desired by dilution with a suitable volume of PPP. All experiments were completed within three hours of venesection, and results were accepted only if platelets aggregated with $5 \mu \mathrm{mol} / 1$ ADP showed no functional deterioration at the end of the experiment. All glassware used was siliconised (Repelcote, Hopkin and Williams Ltd). Platelets were counted with a Coulter model FN particle counter (Bull et al., 1965) in normal controls, or in triplicate with phase contrast microscopy (Brecher and Cronkite, 1950) if platelets of thombocytopenic patients were used.

MEASUREMENT OF PLATELET AGGREGATION (Born, 1962; Born and Cross, 1963)

Platelet aggregation was measured turbidimetrically at $37^{\circ} \mathrm{C}$ in a Payton dual-channel aggregometer with continuous stirring $(1000 \mathrm{rpm})$ of PRP. The integrated recorder was calibrated for full-scale deflection based on the optical density of PRP and PPP. Aggregating agents in $10 \mu \mathrm{l}$ volumes were added to $0.5 \mathrm{ml}$ PRP, and concentrations were expressed as final cuvette concentrations. The maximal change in optical density of PRP was related to the difference in optical density between PRP and PPP, and the result was expressed as percentage platelet aggregation.

REAGENTS

Adenosine diphosphate (ADP) and epinephrine were supplied by Sigma Chemical Co (St Louis, 
Mo, USA); collagen fibril suspension was supplied by Hormon-Chemie (Munich, West Germany). Bovine albumin was obtained in powdered crystallised form from BDH Chemicals, Poole, UK and a $40-45 \%(w / v)$ aqueous solution was made by layering $50 \mathrm{~g}$ of albumin over the top of $100 \mathrm{ml}$ distilled water, which was left to stand at $4^{\circ} \mathrm{C}$ for 48 hours and then brought to $\mathrm{pH} 7.0$ (Walsh, 1972). Calcium-free Tyrode's solution was prepared according to Walsh (1972).

Concentration of PRP (modified from Walsh, 1972) PRP was prepared and $10 \mathrm{ml}$ was carefully layered onto $1 \mathrm{ml} 40 \%$ bovine albumin in a $10 \mathrm{ml}$ roundbottomed polystyrene tube. The interface between the albumin and PRP was gently agitated with a stirring rod, and the stoppered tube was centrifuged at room temperature for 20 minutes at $2500 \mathrm{~g}$. The platelets were sedimented into a band approximately $0.5 \mathrm{~cm}$ broad. The supernatant PPP was removed with a Pasteur pipette and $10 \mathrm{ml}$ PRP was again added. The process was repeated, if necessary, until PRP-albumin of adequate platelet count was obtained.

Bleeding time was performed by the standardised template Ivy method (Mielke et al., 1969).

Platelet antibody was assayed by a simplified immuno-injury platelet factor 3 release method (Hirschman and Gralnick, 1974).

\section{PATIENTS}

Eight women with chronic immune type thrombocytopenia (ITP) were examined. None had undergone splenectomy at the time of examination.

\section{Results}

\section{EFFECT OF PRP-PLATELET COUNT ON} PLATELET AGGREGATION

Platelet aggregation studies with $0.5 \mu \mathrm{mol} / 1$ ADP, $5 \mu \mathrm{mol} / \mathrm{l} \mathrm{ADP}$, and $3 \mathrm{mg} / \mathrm{l}$ collagen were performed on PRP prepared from six normal subjects. The PRP was diluted with PPP to platelet counts varying between 300 and $15 \times 10^{9} / 1$. The results of six sets of serially diluted platelet specimens are given in Table 1.

Since aggregation induced by the same aggregating agent varies in different individuals, platelet aggregation induced in $300 \times 10^{9} / 1-$ PRP was regarded as $100 \%$ and all other results were adjusted proportionately for comparison. Aggregation induced by ADP and collagen was reproducible and acceptable, considering the relative crudity of the test method, at platelet counts as low as $30 \times 10^{9} / 1$.
Table 1 Platelet aggregation induced by ADP and collagen added to $P R P$ with varying platelet counts

\begin{tabular}{|c|c|c|c|}
\hline \multirow{2}{*}{$\begin{array}{l}\text { PRP plotelet count } \\
\left(\times 10^{9} / l\right)\end{array}$} & \multicolumn{3}{|c|}{ Platelet aggregation $(\%)$ induced by } \\
\hline & $0.5 \mu \mathrm{mol} / \mathrm{l} A D P$ & $5 \mu \mathrm{mol} / \mathrm{l} A D P$ & $3 \mathrm{mg} / \mathrm{l}$ collagen \\
\hline 300 & 100 & 100 & 100 \\
\hline 200 & 100 & 100 & 100 \\
\hline 75 & $98-100$ & $94-100$ & $94-100$ \\
\hline 30 & $83-100$ & $83-91$ & $88-92$ \\
\hline 20 & $36-45$ & $35-54$ & $47-58$ \\
\hline 15 & $20-28$ & $28-42$ & $3-6$ \\
\hline
\end{tabular}

The aggregation induced in $300 \times 10 \%$-PRP was regarded as $100 \%$ and all other results were calculated proportionately.

EFFECT OF CONCENTRATION PROCEDURE ON AGGREGATION OF NORMAL PLATELETS

Platelet aggregation of a normal subject was measured on PRP with platelet count $300 \times 10^{9} / 1$ with $5 \mu \mathrm{mol} / 1 \mathrm{ADP}$ and $3 \mathrm{mg} / \mathrm{l}$ collagen as aggregating agents. The PRP was then subjected to a single cycle of the platelet concentration procedure. The PRPalbumin/concentrate was then rediluted to a PRP platelet count of $300 \times 10^{9} / 1$. Dilution was with PPP and/or Tyrode's solution in varying proportions. Platelet aggregation was reassessed with ADP and collagen. Results are given in Table 2. PRP reacted no differently to ADP and collagen after the concentration procedure compared to the contros untreated PRP. Dilution of the concentrate witi $\infty$ either PPP or Tyrode's solution did not affect plate let aggregation.

Table 2 Platelet aggregation induced by $A D P$ and collagen added to mixtures of PRP, PPP, and Tyrode's solution

\begin{tabular}{|c|c|c|c|c|}
\hline \multicolumn{3}{|c|}{$\begin{array}{l}\text { Dilution of concentrated PRP with PPP } \\
\text { and Tyrode's solution }(\mathrm{ml})\end{array}$} & \multirow{2}{*}{$\begin{array}{l}\% \text { Aggregation } \\
5 \mu \mathrm{mol} / \mathrm{l} A D P\end{array}$} & \multirow{2}{*}{$\begin{array}{l}\text { induced by } \\
\begin{array}{l}3 \text { mg/l } \\
\text { collagen }\end{array}\end{array}$} \\
\hline$P R P$ & $\boldsymbol{P P P}$ & Tyrode's & & \\
\hline $\begin{array}{l}2 \\
1 \\
1 \\
1 \\
1 \\
1 \\
\text { Contr }\end{array}$ & $\begin{array}{l}- \\
1 \\
0 \cdot 75 \\
0 \cdot 5 \\
0 \cdot 25 \\
\overline{\text { (unco }}\end{array}$ & $\begin{array}{l}- \\
\overline{0.25} \\
0.5 \\
0.75 \\
1 \\
\text { ted) }\end{array}$ & $\begin{array}{l}58 \\
56 \\
55 \\
52 \\
53 \\
60 \\
61\end{array}$ & $\begin{array}{l}59 \\
58 \\
55 \\
55 \\
52 \\
58 \\
61\end{array}$ \\
\hline
\end{tabular}

The effect of the concentration procedure on platelet aggregation was also assessed by another means. Aggregation response to ADP and collagen of normal subjects' PRP adjusted to a platelet count of $300 \times 10^{9} / 1$ was measured. The PRP was diluted to a platelet count of $30 \times 10^{9} / 1$ with the subject's own PPP and then concentrated to a PRP with a platelet count of $180 \times 10^{9} / 1$. Retesting aggregation 
of this concentrated PRP with $5 \mu \mathrm{mol} / 1$ ADP and 3 $\mathrm{mg} / \mathrm{l}$ collagen revealed comparable percentage aggregation in all three experiments (Table 3). A secondary aggregation wave could not be demonstrated in platelets centrifuged into the albumin gradient (Figure).

PLATELET FUNCTIONS IN PATIENTS WITH ITP The platelets of the eight patients with ITP were subjected to the concentration procedure for only

Table 3 Platelet aggregation induced by ADP and collagen before and after subjecting platelets to the concentration procedure

\begin{tabular}{|c|c|c|c|c|}
\hline \multirow[t]{3}{*}{ Experiment } & \multicolumn{4}{|c|}{ Platelet aggregation (\%) } \\
\hline & \multicolumn{2}{|c|}{$P R P 300 \times 10^{\circ} / l$} & \multicolumn{2}{|c|}{$\begin{array}{l}P R P(\text { reconcentrated }) \\
180 \times 10^{\circ} / l\end{array}$} \\
\hline & 5 umolll ADP & $\begin{array}{l}3 \text { mg/l } \\
\text { collagen }\end{array}$ & $5 \mu \mathrm{mol} / \mathrm{l} A \mathrm{DP}$ & $\begin{array}{l}3 \text { mg/l } \\
\text { collagen }\end{array}$ \\
\hline $\begin{array}{l}1 \\
2 \\
3 \\
\text { Reference } \\
\text { values } \\
( \pm 1 \text { SD) }\end{array}$ & $\begin{array}{l}65 \\
70 \\
60 \\
71 \pm 25\end{array}$ & $\begin{array}{l}80 \\
55 \\
75 \\
70 \pm 26\end{array}$ & $\begin{array}{l}75 \\
75 \\
70\end{array}$ & $\begin{array}{l}75 \\
60 \\
80\end{array}$ \\
\hline
\end{tabular}

one cycle to minimise mechanical injury to platelets. Details of platelet count and function are given in Table 4.

On the basis of in vitro platelet aggregation results the patients can clearly be divided into two groups: four patients with normal platelet aggregation and four with qualitative platelet defect. The group with an in vitro functional defect all had more prolonged standardised bleeding times compared with that of the normal platelet function patients. In none of the patients with normal platelet function could a serum platelet antibody be demonstrated whereas all four patients with thrombopathia had a platelet antibody.

\section{Discussion}

The in vitro study of platelet function in an aggregometer (Born, 1962) is a useful and simple method for assessing qualitative platelet defects if certain variables such as rate of stirring and temperature are carefully controlled (Weiss, 1972). The method requires a reasonable concentration of platelets in the PRP, and since this is usually standardised at about $300 \times 10^{9} / 1$, the method cannot readily be applied

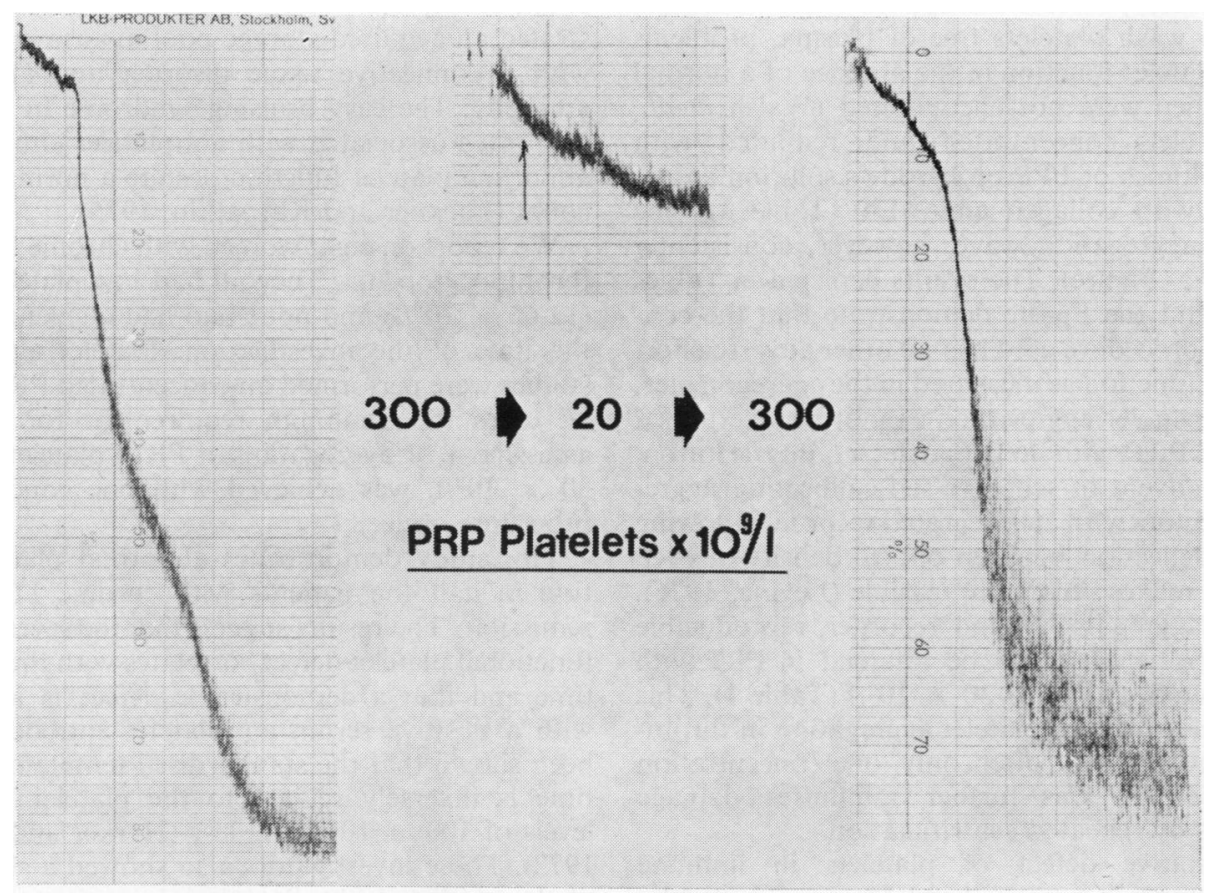

Figure Platelet aggregation induced by $5 \mu$ molll ADP measured in PRP before and after dilution and reconcentration of the same specimen. 
Table 4 Platelet aggregation, bleeding time, and S-platelet antibody results in eight patients with chronic idiopathic thrombocytopenic purpura

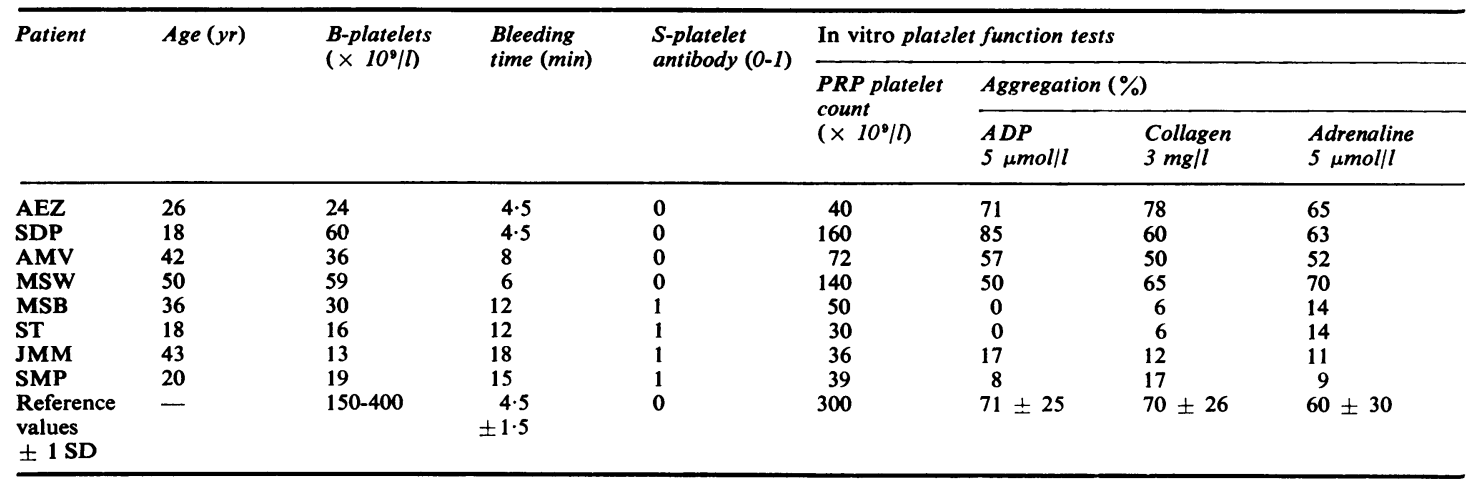

to patients with thrombocytopenia. Concentrated platelets may be achieved by using a density gradient of sucrose (Sanderson, 1973) or albumin (LevyToledano and Bodevin, 1973). We have modified the albumin density gradient separation method of Walsh (1972) to concentrate platelets. The platelets of the PRP are sedimented into a density gradient between plasma and albumin. Physical injury to platelets is minimised since the gradient provides a cushion, which prevents disruption. Since we do not attempt to wash platelets free of plasma, problems affecting platelet function in the absence of a normal plasma milieu were not encountered (Walsh et al., 1977). Platelets concentrated and rediluted with varying volumes of PPP or Tyrode's solution aggregated well with collagen and ADP (Table 2). The secondary aggregation wave, however, consistently disappeared (Figure). The results depicted in Tables 2 and 3 and the Figure demonstrate that the concentration procedure used has no other adverse effect on platelet function as measured in the aggregometer. Although platelet aggregation cannot be determined reliably on PRP with low platelet counts (Hutton, 1966), the advent of sensitive self-calibrating aggregating detectors with an integrated recorder, allowing full-scale deflection between optical density of PRP and PPP, makes this more feasible (Levine, 1976). With our aggregometer and recorder, reproducible aggregation curves could be attained in PRP with platelet counts as low as $30 \times 10^{9} / 1$ (Table 1). This allowed assessment of platelet aggregation in thrombocytopenic patients after only one concentration cycle procedure. This further minimises damage to platelets by repeated centrifugation.

A qualitative defect of platelets in immune thrombocytopenic purpura has been documented by Clancy et al. (1972) and the association of antiplatelet antibody and functional platelet disorders confirmed (Regan et al., 1974; Zahavi and Marder,
1974). Clancy's 11 patients with chronic autoimmune thrombocytopenic purpura in remission, 10 of whom had had splenectomy, all had platelet counts greater than $140 \times 10^{9} / 1$. All but two of these had impaired platelet aggregation, and the severity of the platelet defect correlated with the course of the disease. In 1974 Karpatkin's group described abnormal platelet function in 12 of 21 consecutive patients with systemic lupus erythematosus (Regan et al., 1974), and Zahavi and Marder (1974) demon strated an acquired storage pool disease in a patient with a connective tissue disorder and antiplatele antibody. The easy bruising syndrome in women is also often associated with antiplatelet antibody and abnormal platelet function despite a normal platelet count (Lackner and Karpatkin, 1975).

We report on eight women with chronic idiopathic thrombocytopenia. They all had low platelet counts $\left(13-60 \times 10^{9} / 1\right)$ and none had had a splenectomy at the time of the investigation. Platelet aggregation studies were performed on concentrated PRP, and in all cases the minimum requirement for adequate assessment of aggregation, a PRP- platelet count of $30 \times 10^{9} / 1$, was achieved with one concentration procedure cycle.

This study demonstrates abnormal platelet function in half the patients with chronic ITP not in remission. The results suggest that the severity of the functional platelet defect correlates with the bleeding time and that a demonstrable defect is associated with a positive serum antiplatelet antibody. It has been shown that the standardised template bleeding time is inversely related to the platelet count at levels of $100 \times 10^{\%} / 1$ and less (Harker and Slichter, 1972). These investigators also showed a shortening of the predicted bleeding time in patients with ITP and suggested that these platelets have enhanced haemostatic capacity, confirming previous animal and in vitro studies (Hirsh et al., 1968; Karpatkin, 
1969). Our small series confirms this relationship between a short bleeding time and a low platelet count in ITP. The association between antiplatelet antibody and functional platelet disorders has been suggested by other reports (Clancy et al., 1972; Lackner and Karpatkin, 1975). Clancy et al. (1972) found an inhibitor of platelet aggregation in the globulin fraction of serum from patients with ITP and platelet functional defects. The antiplatelet function factor could be specifically removed with antihuman IgG, suggesting that it was an IgG antibody. We measured antiplatelet antibody by the platelet factor 3 immuno-injury technique (Hirschman and Gralnick, 1974), and in this group of patients it was positive in four of the eight patients. As is evident (Table 4), all patients with demonstrable serum antiplatelet antibody had severe functional in vitro aggregation defects, lower platelet counts, and more prolonged bleeding times than the other four patients. Our results are in agreement with the finding that antiplatelet antibody causes immunoinjury to platelets with resultant functional defects.

These studies have demonstrated that platelets can be concentrated adequately by albumin density gradient separation with no deterioration of their in vitro aggregation response. The method was applied successfully in the study of platelet function in thrombocytopenic subjects with chronic ITP. It appears to be a useful technique which, because of its relative simplicity, may be used routinely, giving reproducible results comparable to that of standard platelet aggregation techniques.

This study was supported by the South African Medical Research Council.

\section{References}

Born, G. V. R. (1962). Aggregation of blood platelets by adenosine diphosphate and its reversal. Nature, 194, 927-929.

Born, G. V. R., and Cross, M. J. (1963). The aggregation of blood platelets. Journal of Physiology, 168, 178-195.

Brecher, G., and Cronkite, E. P. (1950). Morphology and enumeration of human blood platelets. Journal of Applied Physiology, 3, 365-377.

Bull, B. S., Schneiderman, M. A., and Brecher, G. (1965). Platelet counts with the Coulter counter. American Journal of Clinical Pathology, 44, 678-688.

Clancy, R., Jenkins, E., and Firkin, B. (1972). Qualitative platelet abnormalities in idiopathic thrombocytopenic purpura. New England Journal of Medicine, 286, 622626.

Harker, L. A., and Slichter, S. J. (1972). The bleeding time as a screening test for evaluation of platelet function. New England Journal of Medicine, 287, 155-159.

Heyns, A. du P., van den Berg, D. J., Potgieter, G. M., and Retief, F. P. (1974). The inhibition of platelet aggregation by an aorta intima extract. Thrombosis et Diathesis Haemorrhagica, 32, 417-431.

Hirsh, J., Glynn, M. F., and Mustard, J. F. (1968). The effect of platelet age on platelet adherence to collagen. Journal of Clinical Investigation, 47, 466-473.

Hirschman, R. J., and Gralnick, H. R. (1974). A simplified platelet factor 3 (PF-3) assay for the rapid detection of platelet isoantibodies and an antiplatelet factor in ATP and SLE. Journal of Laboratory and Clinical Medicine, 84, 292-297.

Hutton, R. A. (1966). Tests of platelet function and their use in the investigation of bleeding disorders. Journal of Medical Laboratory Technology, 23, 161-185.

Karpatkin, S. (1969). Heterogeneity of human platelets. II. Functional evidence suggestive of young and old platelets. Journal of Clinical Investigation, 48, 10831087.

Lackner, H., and Karpatkin, S. (1975). On the "easy bruising" syndrome with normal platelet count. Annals of Internal Medicine, 83, 190-196.

Levine, P. H. (1976). The effect of thrombocytopenia on the determination of platelet aggregation. American Journal of Clinical Pathology, 65, 79-82.

Levy-Toledano, S., and Bodevin, E. (1973). Technique d'isolement des plaquettes sur gradient d'albumine. Application à l'étude de l'agrégation dans les thrombocytopénies. Nouvelle Revue Française $d$ ' Hématologie, 13, 537-542.

Mielke, C. H. Jr., Kaneshiro, M. M., Maher, I. A., Weiner, J. M., and Rapaport, S. I. (1969). The standardised normal Ivy bleeding time and its prolongation by aspirin. Blood, 34, 204-215.

Regan, M. G., Lackner, H., and Karpatkin, S. (1974). Platelet function and coagulation profile in lupus erythematosus. Studies in 50 patients. Annals of Internal Medicine, 81, 462-468.

Sanderson, J. H. (1973). A method for concentrating platelets for direct studies of platelet aggregation in thrombocytopenia. Scandinavian Journal of Haematology, 11, 356-359.

Walsh, P. N. (1972). Albumin density gradient separation and washing of platelets and the study of platelet coagulant activities. British Journal of Haematology, 22, 205-217.

Walsh, P. N., Mills, D. C. B., and White, J. G. (1977). Metabolism and function of human platelets washed by albumin density gradient separation. British Journal of Haematology, 36, 281-296.

Weiss, H. J. (1972). Platelet aggregation. In Hematology, edited by W. J. Williams, E. Beutler, A. J. Erslev, and R. W. Rundles, p. 1415. McGraw-Hill, New York.

Zahavi, J., and Marder, V. J. (1974). Acquired "storage pool disease" of platelets associated with circulating antiplatelet antibodies. American Journal of Medicine, 56, 883-890.

Requests for reprints to: Professor A. du P. Heyns, Department of Haematology, Faculty of Medicine, The University of the Orange Free State, PO Box 339, Bloemfontein 9300, South Africa. 